\title{
Diffuse Idiopathic Pulmonary Neuroendocrine Cell Hyperplasia (DIPNECH) - A Case Report of Successful SSA Therapy after Failure of Systemic Corticosteroids
}

\author{
Maja Badovinac ${ }^{1 *}$, Matevz Harlander ${ }^{1}$, Branislava Rankovic ${ }^{2}$ and Marjeta Tercelj ${ }^{1}$ \\ ${ }^{1}$ Department of Respiratory Diseases and Allergy, University Medical Centre Ljubljana, Slovenia \\ ${ }^{2}$ Institute of Pathology, University of Ljubljana, Korytkova 2, Slovenia
}

*Corresponding author: Maja Badovinac, MD, Department of Respiratory Diseases and Allergy, University Medical Centre Ljubljana, Zaloška 7, 1000 Ljubljana, Slovenia, Tel: +386-1-522-1105, Fax: +386-1-255-2347, E-mail: badovinac. maja1@gmail.com

\begin{abstract}
Treatment of diffuse idiopathic pulmonary neuroendocrine cell hyperplasia (DIPNECH) has not been established yet. The majority of patients is treated with glucocorticoids. This article presents a case when such treatment was inefficient. When switched to somatostatin analogues treatment, patient's clinical condition and radiologic findings improved. Nonetheless, we were not able to prove the expression of somatostatin receptors in the lung nodules. Somatostatin analogues normally act through these receptors, yet it is possible that indirect mechanisms are involved as well. We suggest somatostatin analogues should be implemented as standard treatment for DIPNECH, regardless the presence of somatostatin receptors on lung nodules.
\end{abstract}

\section{Keywords}

DIPNECH, Somatostatin analogue, Somatostatin receptor, Glucocorticoid

\section{Abbreviations \\ DIPNECH: Diffuse Idiopathic Pulmonary Neuroendocrine Cell Hyperplasia; GC: Glucocorticoids; SSA: Somatostatin Analogues; SSTR: Somatostatin Receptor; eNOS: endo- thelial Nitric Oxide Synthase 3; MAPK: Mitogen-Activated Protein Kinase}

\section{Introduction}

Diffuse idiopathic pulmonary neuroendocrine cell hyperplasia (DIPNECH) is a rare pulmonary syndrome [1]. DIPNECH is affecting predominantly middle-aged, non-smoker women $[2,3]$. Normally it is asymptomat- ic, diagnosed incidentally. The clinical course however, is characterized by slowly progressive, unspecific pulmonary symptoms such as long-lasting dry cough, wheezing and exertional dyspnoea [2,4-8]. Nonetheless, DIPNECH can also cause severe airflow obstruction and respiratory failure which can prove fatal $[2,3,7,9]$.

Diagnosis is made on the basis of correlation of clinical presentation and different imaging techniques and histology. CT displays bronchial wall thickening and mosaic attenuation with air trapping, which are typical for constrictive bronchiolitis. Furthermore, bronchiectasis and typical neuroendocrine nodular aggregates in the lung parenchyma may be visualized by chest CT [2,5$7,10]$. Such nodules can be differentiated into tumorlets $(<5 \mathrm{~mm})$ and carcinoid tumours $(>5 \mathrm{~mm})[5,7,11]$. Chest $\mathbf{x}$-ray is unspecific $[2,6]$. Expression of somatostatin receptors (SSTR) in tumorlets and carcinoids cells is usual in DIPNECH, a characteristic that can be demonstrated by scintigraphy with octreotide or histology [12].

As DIPNECH is a rare and relatively new clinical entity, unanimous treatment guidelines have not been established yet. Different approaches have been tried: Observing stable patients, systemic glucocorticoids (GC) treatment, or chemotherapeutics. Some researchers started propagating usage of bronchodilators and somatostatin analogues (SSAs) $[4,6,7]$. Surgical resections have been suggested for severe cases of the disease, with lung transplantation as the final option $[2,5,6,8]$.

Citation: Badovinac M, Harlander M, Rankovic B, Tercelj M (2018) Diffuse Idiopathic Pulmonary Neuroendocrine Cell Hyperplasia (DIPNECH) - A Case Report of Successful SSA Therapy after Failure of Systemic Corticosteroids. Clin Med Rev Case Rep 5:219. doi.org/10.23937/2378-3656/1410219 Accepted: June 13, 2018: Published: June 15, 2018

Copyright: (c) 2018 Badovinac M, et al. This is an open-access article distributed under the terms of the Creative Commons Attribution License, which permits unrestricted use, distribution, and reproduction in any medium, provided the original author and source are credited. 
Table 1: Clinical course of patient with DIPNECH before and after treatment with SSA.

\begin{tabular}{|c|c|c|c|c|c|c|}
\hline & FVC [\%] & FEV1 [\%] & DLco [\%] & Symptoms & Lung CT & Management \\
\hline 2011 & 85 & 88 & 57 & Present & Numerous small nodules & Surgical procedure \\
\hline 2014 & 75 & 80 & 46 & Present & & \multirow{2}{*}{ GC } \\
\hline 2015 & 81 & 85 & n.d. & Present + GC side effects & & \\
\hline \multirow{2}{*}{2016} & 82 & 83 & 54 & Present & Progression & Surgical procedure \\
\hline & 79 & 60 & 48 & Absent & & \multirow{2}{*}{ SSA } \\
\hline 2017 & 61 & 68 & n.d. & Absent & Stagnation & \\
\hline
\end{tabular}

GC: Glucocorticoids; SSA: Somatostatin Analogues; n.d.: no data.

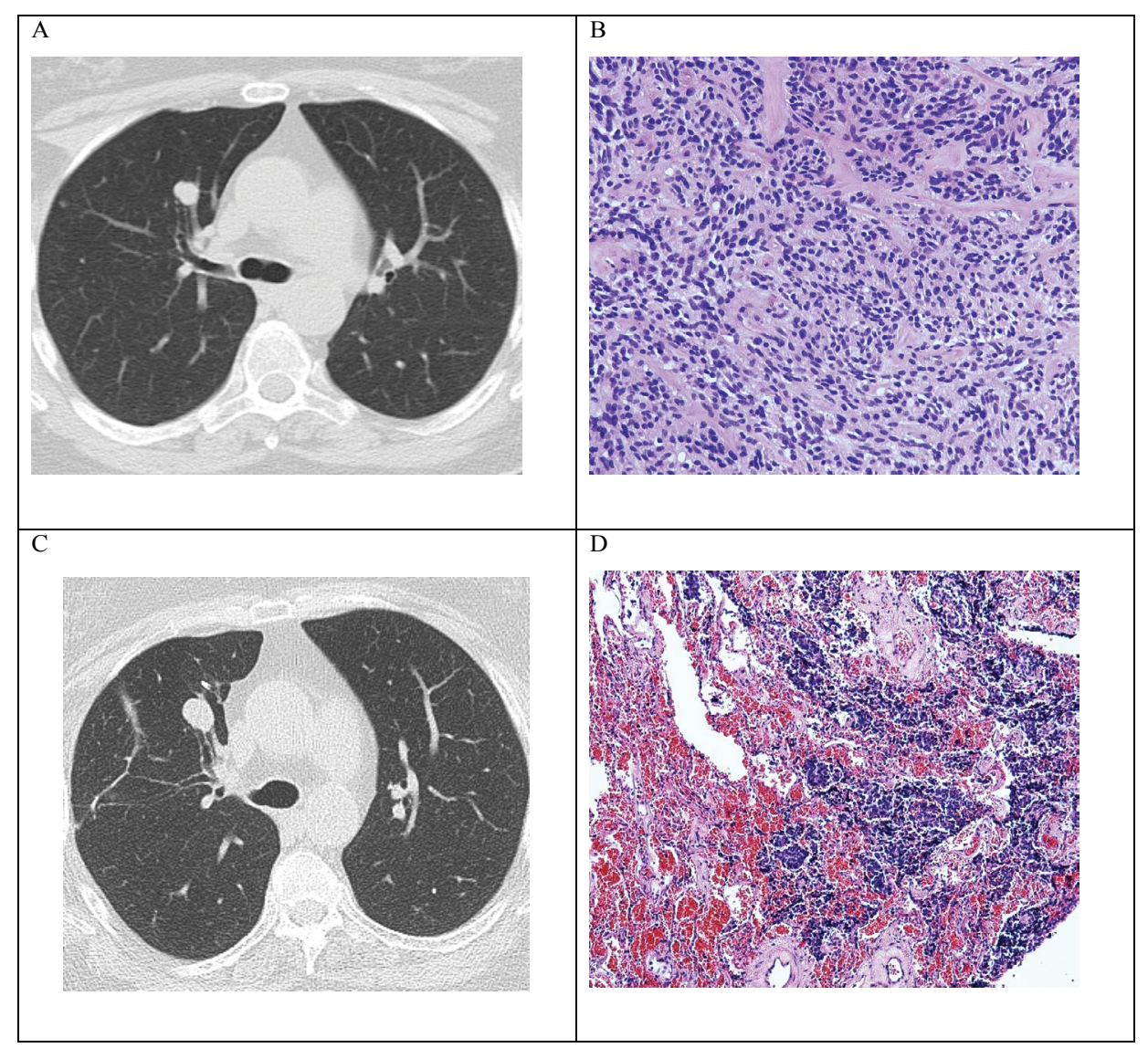

Figure 1: A) CT scan (from 2011) showing numerous small nodules bilaterally, one nodule $11 \times 10 \mathrm{~mm}$ in size in the right upper lobe; B) Histopathology (from 2011) showing solid nests of slightly pleomorphic neuroendocrine cells; C) Follow-up CT scan (from 2016) showing growth of the nodule in anterior right upper lobe, now $15 \times 13 \mathrm{~mm}$ in size; D) Histopathology (from 2016) showing diffuse proliferation of scattered neuroendocrine cells through alveolar parenchyma.

Recently, few small studies have been published suggesting new treatment options. All reported beneficial role of octreotide, a SSA, in patients with DIPNECH [7$9,11,13,14]$.

\section{Case Summary}

In 2011, a 69-year-old, non-smoker female presented with cough, wheezing and progressive dyspnoea. Lung function was normal (Table 1), chest CT was performed (Figure 1a and Table 1).

Surgical biopsy of the biggest nodule was performed. The pathomorphological changes as well as the immunophenotype were consistent with multiple neuroendocrine tumours and tumorlets (Table 1 and Figure 1b).

Accordingly, systemic and inhaled GCs were initiated, alternating 12 and $8 \mathrm{mg}$ daily. Patient's condition improved, but she still had symptoms. These worsened when $\mathrm{GC}$ dose was reduced below $8 \mathrm{mg}$ of GC daily. Additionally, several systemic GC side effects such as cushingoid appearance, osteoporosis with lumboischialgia and severe lumbar scoliosis, parchment skin and unmanageable diabetes appeared. For that reason, after two years of GC therapy, GC were reduced to $8 \mathrm{mg}$ daily.

In 2016, five years after the presentation, the patient started to experience stronger episodes of dry cough, wheezing and dyspnoea. A CT scan demonstrated progression of the biggest nodule (Figure $1 \mathrm{c}$ and Table 1), which was negative on scintigraphy with octreotide (99mTc-HYNIC-octreotide SPECT/CT) suggesting absence of SSTR. The nodule was surgically removed (Table 1 and Figure $1 \mathrm{~d}$ ). The later testing for SSTR was negative, confirming the results of scintigraphy with octreotide. 
Although the tumour did not express SSTR, the patient was recommended a SSA trial therapy (octreotide $20 \mathrm{mg}$ monthly) along with GC treatment discontinuation due to the numerous GC side effects. At the follow-up visit 6 months after SSA initiation, she reported complete clinical improvement without any respiratory symptoms. A CT scan showed stagnation of all the remaining lung nodules (Table 1 ).

\section{Discussion}

We present a case of patient with DIPNECH which was successfully managed with SSA after the failure of oral GC therapy. In the treatment of DIPNECH inhaled or oral GC therapy is most commonly used $[4,6,7,13]$. Accordingly, our patient was first treated with GC but only with mild clinical improvement. There is currently no convincing evidence of efficacy of any therapy for DIPNECH, including SSA [15]. Somatostatin is an inhibitory peptide hormone of the central nervous system [16], also reducing the hormonal hypersecretion of neuroendocrine cells in the gastrointestinal tract and presumably in the bronchial carcinoids, too [17]. Furthermore, it has versatile effects on tumour cells. Antiangiogenic effect via SSTR3 inhibits both endothelial nitric oxide synthase 3 (eNOS) and mitogen-activated protein kinase (MAPK) activities [18]. Proapoptotic function acts via SSTR2 and SSTR3 in cells independent from the induction of apoptosis-related genes, such as p53, p63, p73, Bcl-2, Bax, BID, BIK, TNFSF8, and FADD [19] and also works as an inhibitor of cell invasion through SSTR2. These properties enable it to carry a discrete antitumor function [20]. Two double-blinded randomised studies on SSAs effects in similar mid-gut and pancreatic tumours reported significant benefit in terms of lengthening the time to tumour progression $[21,22]$. To date, there were four case series reported regarding the SSAs therapy in patients with DIPNECH syndrome. These studies reported significant improvement or even complete regression of the respiratory symptoms (especially cough) in almost all patients treated with SSAs $[8,9,13,15]$.

Somatostatin acts through specific receptors, that can be detected on scintigraphy or PET with (68) Ga-labelled SSA or $99 \mathrm{mTC}$-HYNIC-octreotide [23]. When it comes to gastro-entero-pancreatic neuroendocrine tumours, SSAs are most effective when SSTRs are strongly present [24]. The expression of SSTR in DIPNECH is unknown as this was not routinely reported by the authors but it is likely that majority of DIPNECH express SSTR. However, in our case, SSTR were absent on scintigraphy, which was later also confirmed histologically by immunohistochemical staining. In literature there are evidences of superiority of (68) Ga-labelled SSA over 99mTc-HYNIC-octreotide in detecting SSTR $[25,26]$, however at the time of imaging, this indicator was unfortunately not available in our institution yet. Consequently, for detection of SSTR we recommend PET with (68) Ga-labelled SSA.
During our screening of literature, we could not find any study confirming efficiency of SSA in DIPNECH with negative SSTR. Still, these receptors are found in the microenvironment, on endothelial cells as well. All cells expressing SSTRs are then triggered to indirectly, through paracrine pathways, inhibit growth factors and hormones, that normally promote tumour growth [23].

Furthermore, somatostatin impacts tumour growth factor indirectly through inhibition of the growth hormone/insulin-like growth factor-I (GH/IGF-I) axis via central mechanisms (SSTR2 and SSTR5). Somatostatin also works through peripheral mechanisms (SSTR2 or SSTR3) [27]. We could not detect SSTR2 and SSTR5 in our patient's tumour, but these receptors are still present in the microenvironment of her lungs. Accordingly, our patient was treated with octreotide in that manner as well.

At present, there are not many reported studies of indirect mechanisms of somatostatin effects on tumours. The first study we found reported effects through inhibition of $\mathrm{GH}$ in patients with acromegaly [28]. The second and the third studies reported effects through pituitary gland hormones on chondrosarcoma with no SSTR in rats [29] and on pancreatic carcinoma in rats [14]. Yet, after SSA application, our patient's cough and wheezing completely ceased in less than a month. Furthermore, CT showed no progression of the disease even after 6 months on the new therapy.

All the above might be the reason why somatostatin was successful in our patient, in spite of the fact that she is lacking the presence of SSTRs in the removed tumour cells. Still, we do not exclude the possibility that the improvement of our patient's clinical condition was due to the surgical removal of the largest lesion in the lung and consequential reduction of neuroendocrine burden. Another possible explanation of successful treatment with SSA in our patient is our failure to detect all subtypes of SSTR.

\section{Conclusion}

In the described case, SSAs appear to be superior in symptom control compared to usage of systemic GC and show better safety profile. Our case shows that it might be reasonable to attempt SSA trial in symptomatic patients with DIPNECH, even in the absence of SSTR. More data is necessary on the role of SSTR in DIPNECH.

\section{Conflict of Interest}

None.

\section{Funding}

This research did not receive any specific grant from funding agencies in the public, commercial, or not-forprofit sectors.

\section{References}

1. Felton WL, Liebow AA, Lindskog GE (1953) Peripheral and multiple bronchial adenomas. Cancer 6: 555-566. 
2. Nassar AA, Jaroszewski DE, Helmers RA, Colby TV, Patel BM, et al. (2011) Diffuse idiopathic pulmonary neuroendocrine cell hyperplasia: A systematic overview. Am J Respir Crit Care Med 184: 8-16.

3. Rossi G, Cavazza A, Spagnolo P, Sverzellati N, Longo L, et al. (2016) Diffuse idiopathic pulmonary neuroendocrine cell hyperplasia syndrome. Eur Respir J 47: 1829-1841.

4. Aguayo SM, Miller YE, Waldron JA Jr, Bogin RM, Sunday ME, et al. (1992) Brief report: Idiopathic diffuse hyperplasia of pulmonary neuroendocrine cells and airways disease. $\mathrm{N}$ Engl J Med 327: 1285-1288.

5. Travis WD, Brambilla E, Müller-Hermelink HK, Harris CC (2004) Pathology \& genetics: Tumours of the lung, pleura, thymus and heart. World Health Organization classification of tumours, Lyon, IARC Press, France.

6. Davies SJ, Gosney JR, Hansell DM, Wells AU, du Bois RM, et al. (2007) Diffuse idiopathic pulmonary neuroendocrine cell hyperplasia: An under-recognised spectrum of disease. Thorax 62: 248-252.

7. Lee Js, Brown KK, Cool C, Lynch DA (2002) Diffuse Pulmonary Neuroendocrine Cell Hyperplasia: Radiologic and Clinical Features. J Comput Assist Tomogr 26: 180-184.

8. Carr LL, Chung JH, Duarte Achcar R, Lesic Z, Rho JY, et al. (2015) The clinical course of diffuse idiopathic pulmonary neuroendocrine cell hyperplasia. Chest 147: 415-422.

9. Chauhan A, Ramirez RA (2015) Diffuse Idiopathic Pulmonary Neuroendocrine Cell Hyperplasia (DIPNECH) and the Role of Somatostatin analogs: A Case Series. Lung 193: 653-657.

10. Chassagno G, Favelle O, Marchand-Adam S, De Muret A, Revel MP (2015) DIPNECH: When to suggest this diagnosis on CT. Clin Radiol 70: 317-325.

11. Benson RE, Rosado-de-Christenson ML, Martínez-Jiménez S, Kunin JR, Pettavel PP (2013) Spectrum of pulmonary neuroendocrine proliferations and neoplasms. Radiographics 33: 1631-1649.

12. Righi L, Volante $M$, Tavaglione $V$, Billè $A$, Daniele L, et al (2010) Somatostatin receptor tissue distribution in lung neuroendocrine tumours: A clinicopathologic and immunohistochemical study of 218 'clinically aggressive' cases. Ann Oncol 21: 548-555.

13. Gorshtein A, Gross DJ, Barak D, Strenov Y, Refaeli Y, et al. (2012) Diffuse idiopathic pulmonary neuroendocrine cell hyperplasia and the associated lung neuroendocrine tumors clinical experience with a rare entity. Cancer 118: 612-619.

14. Weckbecker G, Raulf F, Bodmer D, Bruns C (1997) Indirect Antiproliferative effect of the somatostatin analog octreotide on MIA PaCa-2 human pancreatic carcinoma in nude mice. Yale J Biol Med 70: 549-554.

15. Wirtschafter E, Walts AE, Liu ST, Marchevsky AM (2015) Diffuse Idiopathic Pulmonary Neuroendocrine Cell Hyperplasia of the Lung (DIPNECH): Current Best Evidence. Lung 193: 659-667.

16. Anthony L, Freda PU (2009) From somatostatin to octreotide LAR: Evolution of a somatostatin analogue. Curr Med Res Opin 25: 2989-2999.

17. Lamberts SW, van der Lely AJ, de Herder WW, Hofland LJ (1996) Octreotide. N Engl J Med 334: 246-254.

18. Florio T, Morini M, Villa V, Arena S, Corsaro A, et al. (2003) Somatostatin inhibits tumor angiogenesis and growth via somatostatin receptor-3-mediated regulation of endothelial nitric oxide synthase and mitogen-activated protein kinase activities. Endocrinology 144: 1574-1584.

19. Ferrante E, Pellegrini C, Bondioni S, Peverelli E, Locatelli $\mathrm{M}$, et al. (2006) Octreotide promotes apoptosis in human somatotroph tumor cells by activating somatostatin receptor type 2. Endocr Relat Cancer 13: 955-962.

20. Chalabi M, Duluc C, Caron P, Vezzosi D, Guillermet-Guibert J, et al. (2014) Somatostatin analogs: Does pharmacology impact antitumor efficacy? Trends Endocrinol Metab 25: 115-127.

21. Rinke A, Müller $\mathrm{HH}$, Schade-Brittinger $\mathrm{C}$, Klose $\mathrm{KJ}$, Barth $P$, et al. (2009) Placebo-controlled, double-blind, prospective, randomized study on the effect of octreotide LAR in the control of tumor growth in patients with metastatic neuroendocrine midgut tumors: A report from the PROMID Study Group. J Clin Oncol 27: 4656-4663.

22. Caplin ME, Pavel M, Ćwikła JB, Phan AT, Raderer M, et al. (2014) Lanreotide in Metastatic Enteropancreatic Neuroendocrine Tumors. N Engl J Med 371: 224-233.

23. Bousquet C, Lasfargues $C$, Chalabi M, Billah SM, Susini C, et al. (2012) Clinical review: Current scientific rationale for the use of somatostatin analogs and mTOR inhibitors in neuroendocrine tumor therapy. J Clin Endocrinol Metab 97: $727-737$

24. Cuccurullo V, Prisco MR, Di Stasio GD, Mansi L (2017) Nuclear Medicine in patients with NET: Radiolabeled somatostatin analogues and their brothers. Curr Radiopharm 10: 74-84.

25. Buchmann I, Henze M, Engelbrecht S, Eisenhut M, Runz A, et al. (2007) Comparison of 68Ga-DOTATOC PET and $111 \mathrm{ln}-\mathrm{DTPAOC}$ (Octreoscan) SPECT in patients with neuroendocrine tumours. Eur $\mathrm{J}$ Nucl Med Mol Imaging 34: 1617-1626.

26. Etchebehere EC, de Oliveira Santos A, Gumz B, Vicente A, Hoff PG, et al. (2014) 68Ga-DOTATATE PET/CT, 99mTc-HYNIC-octreotide SPECT/CT, and whole-body MR imaging in detection of neuroendocrine tumors: A prospective trial. J Nucl Med 55: 1598-1604.

27. Murray RD, Kim K, Ren SG, Chelly M, Umehara $Y$, et al. (2004) Central and peripheral actions of somatostatin on the growth hormone-IGF-I axis. J Clin Invest 114: 349-356.

28. Acromegaly Therapy Consensus Development Panel (1994) Consensus statement: Benefits versus risks of medical therapy for acromegaly. Am J Med 97: 468-473.

29. Redding TW, Schally AV (1983) Inhibition of growth of the transplantable rat chondrosarcoma by analogs of hypothalamic hormones. Proc Natl Acad Sci U S A 80: 1078-1082. 